\title{
Universiteit
}

Leiden

The Netherlands

\section{Is intensity of plant root mycorrhizal colonization a good proxy for plant growth rate, dominance and decomposition in nutrient poor conditions?}

Elumeeva, T.G.; Onipchenko, V.G.; Cornelissen, J.H.C.; Semenova, G.V.; Perevedentseva, L.G.; Freshet, G.T.; ... ; Soudzilovskaia, N.A.

\section{Citation}

Elumeeva, T. G., Onipchenko, V. G., Cornelissen, J. H. C., Semenova, G. V., Perevedentseva, L. G., Freshet, G. T., ... Soudzilovskaia, N. A. (2018). Is intensity of plant root mycorrhizal colonization a good proxy for plant growth rate, dominance and decomposition in nutrient poor conditions? Journal Of Vegetation Science, 29(4), 715-725. doi:10.1111/jvs.12651

Version: $\quad$ Publisher's Version

License: $\quad$ Licensed under Article 25fa Copyright Act/Law (Amendment Taverne)

Downloaded from: https://hdl.handle.net/1887/3202855

Note: To cite this publication please use the final published version (if applicable). 


\title{
Is intensity of plant root mycorrhizal colonization a good proxy for plant growth rate, dominance and decomposition in nutrient poor conditions?
}

\author{
Tatiana G. Elumeeva ${ }^{1}$ (D) | Vladimir G. Onipchenko ${ }^{1}$ | Johannes H. C. Cornelissen ${ }^{2}$ | \\ Galina V. Semenova $^{3}$ | Lidia G. Perevedentseva ${ }^{4}$ | Grégoire T. Freschet ${ }^{5}$ | \\ Richard S. P. van Logtestijn ${ }^{2}$ | Nadejda A. Soudzilovskaia ${ }^{6}$
}

${ }^{1}$ Department of Geobotany, Biological Faculty, Lomonosov Moscow State

University, Moscow, Russia

${ }^{2}$ Systems Ecology, Department of Ecological Science, Faculty of Earth and Life Sciences, Vrije University Amsterdam, Amsterdam, The Netherlands

${ }^{3}$ Department of Plant Ecology, Uppsala University, Uppsala, Sweden

${ }^{4}$ Department of Botany and Plant Genetics, Faculty of Biology, Perm State University, Perm, Russia

${ }^{5}$ Centre d'Ecologie Fonctionnelle et Evolutive, UMR 5175 (CNRS - Université de Montpellier - Université Paul-Valéry Montpellier - EPHE) Montpellier, France

${ }^{6}$ Environmental Biology Department, Institute of Environmental Sciences, CML, Leiden University, Leiden, The Netherlands

\section{Correspondence}

Tatiana G. Elumeeva, Department of Geobotany, Biological Faculty, Lomonosov Moscow State University, Moscow, Russia. Email: elumeeva@yandex.ru

Funding information

Russian Science Foundation, Grant/Award Number: 16-14-10208; Nederlandse Organisatie voor Wetenschappelijk Onderzoek, Grant/Award Number: 047.017.010 and 047.018.003

Co-ordinating Editor: Martin Zobel

\begin{abstract}
Questions: Mycorrhizae may be a key element of plant nutritional strategies and of carbon and nutrient cycling. Recent research suggests that in natural conditions, intensity of mycorrhizal colonization should be considered an important plant feature. How are inter-specific variations in mycorrhizal colonization rate, plant relative growth rate (RGR) and leaf litter decomposability related? Is (arbuscular) mycorrhizal colonization linked to the dominance of plant species in nutrient-stressed ecosystems? Location: Teberda State Biosphere Reserve, northwest Caucasus, Russia.

Methods: We measured plant RGR under mycorrhizal limitation and under natural nutrition conditions, together with leaf litter decomposability and field intensity of mycorrhizal colonization across a wide range of plant species, typical for alpine communities of European mountains. We applied regression analysis to test whether the intensity of mycorrhizal colonization is a good predictor of RGR and decomposition rate, and tested how these traits predict plant dominance in communities.

Results: Forb species with a high level of field mycorrhizal colonization had lower RGR under nutritional and mycorrhizal limitation, while grasses were unaffected. Litter decomposition rate was not related to the intensity of mycorrhizal colonization. Dominant species mostly had a higher level of mycorrhizal colonization and lower RGR without mycorrhizal colonization than subordinate species, implying that they were more dependent on mycorrhizal symbionts. There were no differences in litter decomposability. Conclusions: In alpine herbaceous plant communities dominated by arbuscular mycorrhizae, nutrient dynamics are to a large extent controlled by mycorrhizal symbiosis. Intensity of mycorrhizal colonization is a negative predictor for whole plant RGR. Our study highlights the importance of mycorrhizal colonization as a key trait underpinning the role of plant species in carbon and nutrient dynamics in nutrient-limited herbaceous plant communities.
\end{abstract}

KEYWORDS

alpine communities, dominance, litter decomposition, mycorrhizae, relative growth rate 


\section{1 | INTRODUCTION}

Most alpine ecosystems above the natural tree line have low nutrient availability, slow nutrient cycling, slow-growing plant species and low net primary productivity. These are typical for ecosystems featuring fungal dominance in the soil (Bardgett \& Wardle, 2010; van der Heijden, Bardgett \& van Straalen, 2008). Fungi are involved in a wide spectrum of ecosystem processes related to carbon (C) and nutrient cycling, particularly nutrient uptake and organic matter decomposition (Cornelissen, Aerts, Cerabolini, Werger \& van der Heijden, 2001; Langley \& Hungate, 2003). Mycorrhizal fungi, which form a symbiotic relationship with higher plants and supply them with nutrients in exchange for $C$ compounds, are particularly important for ecosystem primary productivity (Smith \& Read, 2008; van der Heijden, Martin, Selosse \& Sanders, 2015). Consequently, in relatively infertile ecosystems, mycorrhizae play a major role in C and energy fluxes (Allen, Swenson, Querejeta, Egerton-Warburton \& Treseder, 2003). Mycorrhizal fungi provide host plants with water and nutrients. In particular, phosphorus $(P)$ is supplied through arbuscular mycorrhizae (AM) and nitrogen (N) through ericoid- and ectomycorrhizae, although arbuscular mycorrhizal fungi may also enhance $\mathrm{N}$ acquisition under some conditions (Hodge, Campbell \& Fitter, 2001; Leigh, Hodge \& Fitter, 2009; Nuccio et al., 2013). In exchange, the plants provide the fungi with $C$, and export of assimilates to hyphae should result in reduced plant growth, if not balanced by enhanced photosynthesis. The growth responses of plants to mycorrhizae vary from negative to positive in different species (Konvalniková, Püschel, Řezáčová, Gryndlerová \& Jansa, 2017) and depend on both nutrient (mostly P) and C limitation (Son \& Smith, 1988), as well as on how the plant controls $C$ fluxes to the symbionts (Jin, Wang, Wang, Wang \& Gange, 2017). In nutrient-poor environments, benefits of acquisition of additional mineral nutrients compensate for the costs of plant C losses (Aikio \& Ruotsalainen, 2002; Allen et al., 2003; Birhane, Sterck, Fetene, Bongers \& Kuyper, 2012). In a metaanalysis of experimental manipulations of intensity of AM infection, Treseder (2013) showed that, notwithstanding large variability, the percentage of plant root length colonized by AM fungi is generally correlated with the effect size of plant biomass response (i.e. ratio of biomass of plants with high mycorrhizal colonization to plants with low rate of colonization). This suggests that the underlying mechanism for this phenomenon is a mycorrhiza-induced increase in transfer of nutrients to the plants. The intensity of plant root mycorrhizal colonization of a given plant species is known to vary according to season (Ruotsalainen, Väre \& Vestberg, 2002), plant age (Sogonov et al., 2004), soil conditions (Smith \& Read, 2008) and fungal species identity (Chagnon, Bradley, Maherali \& Klironomos, 2013; Treseder, 2013). However, recently Soudzilovskaia et al. (2015) demonstrated on a global data set that the intensity of mycorrhizal colonization for a given mycorrhizal type showed consistent variation among species and could therefore be used as an important plant feature for comparative analysis with other plant functional traits.
Although the ability of plant species to establish a symbiosis with a particular group of mycorrhizal fungi is an important functional trait (Cornelissen et al., 2001; Moora, 2014; Soudzilovskaia et al., 2015), our understanding of the contribution of arbuscular mycorrhizae to the processes shaping vascular plant community structure is still poor. It has been suggested that, through improvement to plant nutrition, mycorrhizal symbiosis allows subordinate AM plant species to retain their presence in a plant community (Grime, Mackey, Hillier \& Read, 1987; Mariotte et al., 2013; Stanescu \& Maherali, 2017b). At the same time, AM in dominant species may reinforce their competitive ability (Gross et al., 2010; Hartnett \& Wilson, 1999; McCain, Wilson \& Blair, 2011; Selivanov, 1981). However, the exact mechanisms connecting mycorrhizae and abundance of a particular plant species in an ecosystem are still unclear.

Relative growth rate (RGR) is an inherent plant trait, one of the main components of which is specific leaf area (Atkin, Botman \& Lambers, 1996; Garnier, Navas \& Grigulis, 2016). RGR, which is typically measured in pot experiments with non-limiting nutrients, is among the most important traits characterizing plant life strategy across habitats (Garnier et al., 2016; Grime, Hodgson \& Hunt, 1988). In disturbed or productive habitats fast-growing plant species are dominant, while nutrient-poor environments are usually dominated by stress-tolerant plant species. In nutrient-poor soils of the alpine belt of the northwestern Caucasus, dominant stresstolerant plant species have lower RGR than fast-growing subordinate species (Onipchenko, Semenova \& van der Maarel, 1998). In contrast, more fertile ecosystems at earlier successional stages are dominated by species with higher RGR, with RGR decreasing towards relatively nutrient-impoverished later successional stages (Kazakou, Vile, Shipley, Gallet \& Garnier, 2006).

Inter-specific variation in litter decomposition rates has been shown to be strongly related to the position of plant species along a "plant economics spectrum", represented by functional traits, such as carbon and $\mathrm{N}$ content, $\mathrm{C} / \mathrm{N}$ and lignin/ $\mathrm{N}$ ratios of plant above- and below-ground organs (Freschet, Aerts \& Cornelissen, 2012). Thus, litter decomposability reflects both variation in living plant traits and their nutrient acquisition strategies. In infertile habitats, litter is an important source of nutrients, and decomposability of plant organs is both an important proxy for and consequence of resource availability (Fortunel et al., 2009). Furthermore litter accumulation strongly affects vegetation structure, changing plant habitat by modifying temperature and humidity, with knock-on effects on seed germination (Xiong \& Nilsson, 1999). Besides, species forming a dense layer of litter can enforce their dominance by preventing recruitment of other species (Facelli \& Pickett, 1991).

The complex linkages between plant RGR, decomposability and root mycorrhizal colonization intensity across plant species in communities, together covering key aspects of biogeochemical cycles in ecosystems, have to our knowledge never been investigated together, although some aspects of these relationships have been reported. As RGR and leaf decomposability are linked through plant traits, i.e. well defended, long-lived leaves of species with inherently 
low RGR produce relatively recalcitrant litter (Bardgett, 2017), enabling a positive relationship between RGR and litter decomposability across species (Cornelissen et al., 2001).

For a given species, individual plants infected by mycorrhizal fungi were found to have higher RGR in low-nutrient soils compared to those grown without mycorrhiza (e.g. Aikio \& Ruotsalainen, 2002). At inter-specific level, mycorrhizal growth response of grassland species varies from neutral to positive, and is negatively correlated with intrinsic growth rate of seedlings (Stanescu \& Maherali, 2017a). Thus mycorrhizal association enables inherently slow-growing species that feature strong mycorrhizal growth response (at the level of individual plants) to have a competitive advantage compared to fast-growing species (Stanescu \& Maherali, 2017b). For such species it is important to rapidly establish symbiosis within a common mycorrhizal network in order to achieve a high level of root colonization (Varga \& Kytöviita, 2016). In contrast, fast-growing herbaceous ruderal plant species often have low rates of mycorrhizal colonization (Onipchenko \& Zobel, 2000). In the case of disturbance, the mycorrhizal network is disrupted and plants need to grow without a symbiosis at least initially (Smith, Facelli, Pope \& Smith, 2010). At the same time, additional nutrients become available in the soil, and plants can themselves reduce colonization rate of AM fungi (Konvalniková et al., 2017). Francis and Read (1995) even argued that ruderal species experience antagonistic effects of AM fungi. Such mechanisms would also explain why plant species colonizing gaps in grassland vegetation tend to have relatively low rates of mycorrhizal colonization, thus species that usually prefer such gaps have lower rates of mycorrhizal colonization in the field (Onipchenko \& Zobel, 2000).

The role of mycorrhizae in plant litter decomposition is not yet well understood. Arbuscular mycorrhizal hyphae generally do not appear to be involved in decomposition of recalcitrant organic matter (Rillig \& Allen, 1999), but at least some AM fungal species may acquire inorganic $\mathrm{N}$ from less recalcitrant organic sources and thereby provide host plants with $\mathrm{N}$ (Herman, Firestone, Nuccio \& Hodge, 2012; Hodge et al., 2001; Leigh et al., 2009). Also, AM fungi may mediate soil microbial activity, which in turn affects decomposition processes (Herman et al., 2012; Nuccio et al., 2013). For a given species, mycorrhizal colonization indirectly contributes to plant litter decomposition through improving the host plant's nutrient status, and thus the quality of litter shed (Schädler, Brandl \& Kempel, 2010). However, as mentioned above, at inter-specific level, higher mycorrhizal dependency of inherently slow-growing species with recalcitrant litter suggests a negative relationship between mycorrhizal colonization and litter decomposability.

The growth of vascular plants in alpine ecosystems is strongly constrained by suboptimal temperatures, short growing season and consequent nutrient limitation. However, many plant species successfully persist under such conditions. Mycorrhizal symbiosis is likely to be a key feature of this adaptation. As plants influence ecosystem properties and competition outcome both via traits of living organs and organ "afterlife" traits, effects of mycorrhizae could reflect not only the fitness of a growing plant, but also the properties of its litter.

Although mycorrhizae are abundant in nutrient-limited herbaceous communities, such as alpine ecosystems (Soudzilovskaia et al., 2015), the complex interplay of mycorrhizae, nutrient cycling processes and plant community assembly in such environments are poorly understood. Alpine communities are dominated by stress-tolerant species with inherently low RGR (as a consequence of values for underlying traits, such as low specific leaf area; Pierce et al., 2017), so we expect that they will require more fungal support in the field. Taken together, we predict that the relationships between RGR, decomposition rate and mycorrhizal colonization in alpine environments should result in: (a) a negative correlation between RGR and mycorrhizal colonization across species; (b) a positive correlation between RGR and litter decomposability and, as a consequence; (c) a negative correlation between mycorrhizal colonization and litter decomposability. Furthermore, low-quality litter promotes fungal rather than bacterial decomposers and retards nutrient cycling (Bardgett, 2017). Litter accumulation may be a strong tool for plants to change their microenvironment, thus, in alpine communities we expect slow-growing species with recalcitrant litter and a high level of mycorrhizal colonization to dominate. In contrast, species with high RGR could be restricted to sites with periodic soil disturbance (e.g. activity of voles or wild boar), where fungal networks are also often disturbed.

Here we investigate how intensity of mycorrhizal colonization in plant roots is related to plant species' relative abundance in a community, and examine whether this relationship could be explained by other plant functional traits that drive ecosystem nutrient and C cycling and plant community assembly: plant RGR and litter decomposition. In order to understand if and how mycorrhizal colonization in the field helps plants with inherently low growth rates to dominate in alpine ecosystems, one needs to explicitly separate RGR as a plant-only trait from plant root mycorrhizal colonization levels. Such separation is possible when RGR is examined in conditions similar to those in field (i.e. nutrient limitation) but without mycorrhizal symbiosis. We employed this approach in our study. Specifically, we tested whether (a) interspecific variation in intensity of root colonization by mycorrhizal fungi in the field, RGR (measured under nutritional and mycorrhizal limitation under standardized conditions), and decomposability of above-ground plant organs are related; and whether (b) in nutrient-stressed plant communities, dominant species with traits adapted to slow $\mathrm{C}$ and nutrient cycling (low RGR, low decomposability) show higher intensity of root colonization by mycorrhizal fungi compared to sub-dominant plant species. We examined this relationship for plants sampled in four typical alpine communities of the Russian Caucasus, where plant productivity is strongly limited by $\mathrm{N}$ and/or $\mathrm{P}$ (Onipchenko et al., 2012; Soudzilovskaia, Onipchenko, Cornelissen \& Aerts, 2005), and where mycorrhizal fungi are therefore likely to strongly impact plant growth and nutrition, thereby indirectly influencing decomposition processes. 


\section{2 | METHODS}

\section{1 | Study area}

The study was conducted in the Teberda State Biosphere Reserve (northwest Caucasus, Russia), in the alpine belt of Malaya Khatipara Mountain at 2,700-2,800 $\mathrm{m}$ a.s.l. The area has a typical temperate mountain climate. The mean annual temperature is about $-1.2^{\circ} \mathrm{C}$ and mean annual precipitation is $1,400 \mathrm{~mm}$ (Onipchenko, 2004). Soils are Umbric Leptosols (Malysheva, Onipchenko, Makarov, Volkov \& Bulatnikova, 2004).

We studied species of four typical herbaceous alpine communities: alpine lichen heaths (ALH), Festuca varia grasslands (FVG), Geranium gymnocaulon-Hedysarum caucasicum meadows (GHM) and alpine snowbed communities (SBC). ALH occupy windward crests and slopes with low or no snow accumulation in winter; fruticose lichens are the main dominants here. FVG occupy slopes with low snow accumulation of ca. 0.5-1.0 m; the dense tussock grasses F. varia and Nardus stricta prevail in these communities. GHM are located on lower parts of slopes with typical snow depth of 2-3 m; the dominant species are G. gymnocaulon and H. caucasicum. SBC are developed in depressions and bottoms of nival cirques with heavy winter snow accumulation of $4 \mathrm{~m}$ or more, so the vegetative season is only about 2.0-2.5 months; the typical species are Sibbaldia procumbens, Taraxacum stevenii, Minuartia aizoides. As the communities are spatially close to each other, there are no significant differences in temperature and precipitation during the summer season. Soil nutrient content increases from ALH to SBC (Malysheva et al., 2004; Onipchenko, 1994); however, GHM and FVG are the most productive communities. For nomenclature and further details about these communities see Onipchenko (2004) and Onipchenko, Zernov and Vorob'eva (2011).

\section{2 | Species selection}

For this study, we used data sets on vascular plant traits of the Teberda Reserve, for which at least one target trait was measured. The numbers of species were 30 for RGR, 62 for leaf litter decomposition and 87 for mycorrhizal colonization. The examined species are typical for the alpine belt of temperate zone mountains across all four major types of plant communities. When a species was present in more than one community, we sampled it within the community where it was most abundant (i.e. had highest biomass, according to data in Cherednichenko et al., 2004).

The data on 20 species (eight grasses and 12 forbs; see Supporting information Appendix S1 for species list) overlapped across all studied traits, so only these 20 species had both RGR and decomposition data; 28 species had both RGR and mycorrhizal colonization data; 62 species had both decomposition and mycorrhizal colonization data. Biomass sampling, root sampling for mycorrhizae analysis, and litter sampling for the decomposition experiment were performed at the species level, on distinct sets of plant individuals, within one given community.

\section{3 | Mycorrhizal colonization in the field}

We took measures to minimize intra-specific variation in mycorrhizal colonization: we sampled all plants at the same time of year and sampled only adult, well-developed plants. Also, to properly account for this variation and obtain representative species means, we sampled from truly replicate plots of the same plant community (see Supporting information Appendix S1). Roots of alpine plants for mycorrhizal analysis were collected in the second part of August. For each plant species fine roots ( $<2 \mathrm{~mm}$ in diameter) from at least five individual adult plants growing far from each other (at least $100 \mathrm{~m}$, as distinct replication of host plant community) were collected. The latter provision was taken in order to account for variability in mycorrhizal colonization due to variability of soil conditions. Fresh roots were fixed in $4 \%$ formaldehyde solution. Fixed roots were macerated in $20 \% \mathrm{KOH}$ for 2-3 months, and rigid dark roots of several species were additionally heated in the same solution for $1 \mathrm{hr}$ (Onipchenko $\&$ Zobel, 2000). Then the roots were washed and stained with aniline blue ( $0.1 \mathrm{~g}$ aniline blue $+50 \mathrm{~g}$ lactic acid $+100 \mathrm{~g}$ water) for $1 \mathrm{hr}$. After removal of the stain solution, the samples were put in pure lactic acid for $30 \mathrm{~min}$. The root samples were then kept in glycerol and analysed under a microscope. The total number of microscope fields $(\times 120)$ examined was 130-150 for each sample. The amount of AM fungi was estimated on the Selivanov scale (Akhmetzhanova et al., 2012; Selivanov, 1981) from absent (class 0) to very high (class 5): (1) mycorrhizal fungi present in a few mesoderm cells; (2) about a quarter of mesoderm cells occupied by fungi; (3) about half of mesoderm cells are occupied by fungi; (4) about three-quarters of mesoderm cells are occupied by fungi; (5) almost all mesoderm cells are occupied by fungi. The rate of mycorrhizal colonization $(C)$ was calculated as $C=S /(N \times K) \times 100 \%$, where $S$ is the sum of all colonization classes, $N$ is the number of microscope fields, $K$ is the highest class (5) (Sogonov et al., 2004). This method of estimating plant root colonization intensity by AM fungi is similar to, but more fungal abundance-weighted than, the more commonly used estimate of percentage root length colonized by fungi. Nevertheless, the recent work of Akhmetzhanova et al. (2012) demonstrated that data based on these methods are highly correlated with each other. For nine species the data on mycorrhizal colonization rate was extracted from an existing database (Akhmetzhanova et al., 2012); these data were obtained by the same method.

\section{4 | Relative growth rate}

Plant RGR was assessed using a standard protocol (Grime et al., 1988), the main difference being that a low nutrient, nonmycorrhizal regime was used (Onipchenko et al., 1998). For RGR measurements, mature seeds of alpine plants were collected in the Teberda Reserve in 1995. The experiment was conducted in AprilMay 1996 in the greenhouse under natural light and temperature conditions (ca. $5^{\circ} \mathrm{C}$ night and $20^{\circ} \mathrm{C}$ day) at the lab of the Swedish University of Agricultural Sciences, Uppsala. Seeds were coldstratified for 2 months and germinated in Petri dishes prior to the 
experiment start. Newly germinated seedlings were transferred to pots of $50 \mathrm{ml}$ (one seedling per pot) in fine $(3-5 \mathrm{~mm}$ ) granite gravel substrate and grown for 5 weeks. The pots were placed randomly on shallow trays. Every day the position of pots was randomized. Pots were moistened once a day with ten-fold diluted Hewitt's nutrient solution (Grime et al., 1988) to mimic low soil fertility similar to that in natural alpine communities of the Teberda Reserve (Supporting information Appendix S2). The solution was supplied in an amount exceeding substrate absorption capacity, so that a shallow layer of liquid was always present under the pot. Every day, prior to watering, dishes were emptied in order to keep the water fresh. Seedlings of all species were grown simultaneously. Upon harvest, roots (which did not show any clear symptoms of being pot-bound) were carefully washed. Oven-dry mass $\left(105^{\circ} \mathrm{C}\right.$ for $\left.24 \mathrm{hr}\right)$ of entire seedlings was measured at harvests $2\left(t_{1}\right)$ and 5 weeks $\left(t_{2}\right)$ after germination in five replicates of all species, except $F$. varia, which was measured in two replicates as seed germination was very low. RGR was calculated from the formula: $R G R=\left(\ln \left(M_{2}\right)-\ln \left(M_{1}\right)\right) /\left(t_{2}-t_{1}\right)$, where RGR is relative growth rate, $M_{1}$ - mass of seedlings at $t_{1}, M_{2}$ - mass of seedling at $t_{2}$.

\section{5 | Decomposition experiment}

Plant material for the decomposition experiment was sampled using a minimum of 40 plant individuals per species. Leaves, including petioles and rachides, where sampled when fully senesced. Leaf litter samples were then air-dried, and the remaining water content measured on a subsample (dried in oven at $70^{\circ} \mathrm{C}$ for $24 \mathrm{hr}$ ) in order to correct air-dry mass of litterbag samples for residual humidity. For each species, eight subsamples of air-dry litter were weighed and sealed into litter bags with $1 \mathrm{~mm}$ mesh size on the upper side and $0.3 \mathrm{~mm}$ on the lower side (to prevent material falling out). Depending on species, litter mass varied from 0.1 to $1.0 \mathrm{~g}$ so as to standardize litter packing densities and textures inside the bags (Freschet et al., 2012).

Litter was incubated following the 'common garden' litter bed approach with simultaneous incubation of multiple species in the same semi-natural environment (Cornelissen, 1996). Four litter beds (i.e. replicate blocks) were established in grassland dominated by the grass $N$. stricta, which represents an intermediate position in relief and vegetation between F. varia grasslands and GeraniumHedysarum meadows. We filled litter beds with a matrix of mixed litter, including senesced plant organs from the current as well as previous growing season from all four plant communities. Litter bags were arranged randomly within litter beds and covered with a ca. $10 \mathrm{~mm}$ layer of the same mix of litter on 24 September 2009. Each litter bed contained two subsamples of every litter sample.

One litter bag per species and per litter bed was harvested on 23 September 2010 and the second on 23 September 2011. On each occasion we carefully removed any soil particles, small invertebrates, roots of vascular plants and other alien material from the remaining litter samples. These were then dried $\left(70^{\circ} \mathrm{C}, 24 \mathrm{hr}\right)$ and weighed.

We used single exponential models to obtain decomposition constants ( $k$ ) from percentage mass loss against time. Half-lives of decomposing materials ( $T_{1 / 2}$, time [year] needed to reach $50 \%$ mass loss) were derived from their respective decomposition models (Freschet et al., 2012).

\section{6 | Biomass samplings}

To estimate the relative dominance position of different species, we estimated species above-ground biomass in the four target alpine communities by clipping plants on square plots of $25 \mathrm{~m} \times 25 \mathrm{~cm}$. Such size of plots is optimal for handling in alpine communities of the Teberda Reserve due to the small stature of plants (Cherednichenko et al., 2004). The total number of plots sampled was 104 in ALH, 92 in FVG and GHM, and 90 in SBC. The samples were collected over several years, in July-August, eight to 20 plots in the respective study years (ALH was sampled in 1981-1983, 2002, 2003, 2008 and 2010; FVG, GHM and SBC were sampled in 1985-1987, 2002, 2003,2008 ) on visually homogeneous sites of the studied communities. Clipping was done every year in distinct plots, situated in target plant communities at least $10 \mathrm{~m}$ apart from previous sampling locations. Within a community, the plots were established at the same distance from each other without taking into account dominance of a specific plant species. In each plant community all living plants were clipped at ground level. Clipped material was sorted by plant species. Samples were oven-dried $\left(80^{\circ} \mathrm{C}, 24 \mathrm{hr}\right)$ and weighed. Here, we averaged the data and used only data on plant species mean biomass per area and mean percentage of species' biomass relative to total vascular plant biomass. The averaging of biomass data across several years allows estimation of relative species abundance without regard to specific weather conditions and productivity in some years.

\section{7 | Data analysis}

We tested whether the intensity of plant root colonization by mycorrhizal fungi was related to RGR under a limiting nutritional regime and decomposition rate with ordinary least squares (OLS) regressions. As only 20 species had had all the target traits measured, we ran the same models for extended data sets (mycorrhizal colonization vs.RGR - 28 species; mycorrhizal colonization vs decomposition rate - 62 species). Subsequently this analysis was conducted separately for individual functional groups - forbs and grasses - as these groups may differ in mycorrhizal dependence (van der Heijden $\&$ Cornelissen, 2002). Sedges and dwarf shrubs were not analysed because there were only a few species of these plant functional types. Community type was added in the full models as a categorical variable with interaction term to reveal whether these relationships differed between communities. The final model was selected in the course of the backward regression. The $T_{1 / 2}$ values were $\log _{10^{-}}$ transformed to comply with normality assumptions. All numerical data were scaled. We ran this analysis for the total data set as well as for grasses and forbs separately.

To find out whether mycorrhizal colonization, RGR under nutritional limitation and decomposition predict species abundance in the 
typical alpine communities, we ran linear mixed models using the $n / m e$ $\mathrm{R}$ package, with relative abundance (mean percentage of species' biomass relative to total vascular plant biomass, log-transformed) as dependent variable and the studied traits as predictors. Community was treated as a random effect. To assess significance of fixed effects, we fitted null models with only random effects, and compared these null models to models including fixed effects using the likelihood ratio method. The coefficients of determination for variance explained by fixed effects (marginal $R^{2}$ ) were obtained in the R MuMln package using the algorithm of Nakagawa and Schielzeth (2013). Not all the species were observed on the biomass sampling plots, and vegetative shoots of two Carex species (C. umbrosa and C. sempervirens) are difficult to distinguish in the field, so these species were excluded from the analysis of dominance. Thus, we conducted this analysis for individual trait-trait combinations, using 22 species with RGR data, 46 species with decomposition data and 68 species with mycorrhizal colonization data. Statistical analysis was run in the R statistical environment (R Foundation for Statistical Computing, Vienna, Austria).

\section{3 | RESULTS}

Our species represented a wide range of mycorrhizal infection rate, from non-mycorrhizal plants (Rumex alpestris, Supporting information Appendix S1) to species with a high mycorrhizal colonization rate (Erigeron caucasicus, Antennaria dioica). RGR varied from
$0.55 \mathrm{~g} \cdot \mathrm{g}^{-1} \cdot$ week $^{-1}$ in A. dioica to $1.75 \mathrm{~g} \cdot \mathrm{g}^{-1} \cdot$ week $^{-1}$ in Chamaenerion angustifolium. Leaf litter decomposition $T_{1 / 2}$ varied from 0.88 years in Veronica gentianoides to 2.37 years in A. dioica.

Community type did not influence the relationships between mycorrhizal colonization, RGR and decomposition rate (Supporting information Appendix S3), so here we present results of the simple models with only one predictor. Analysed over all plant species (grasses and forbs together), intensity of mycorrhizal colonization was a significant negative predictor for whole plant RGR $(p<0.001$, $R^{2}=0.50$; Figure 1a), i.e. species with a high level of infection were slow-growing, while non-mycorrhizal species and species with a low level of infection were fast-growing (Figure 1a). However, when forbs and grasses were analysed individually, the regression was significant only in forbs $\left(R^{2}=0.56, p=0.005\right)$, not in grasses $(p=0.124)$. The same pattern was observed for the extended data set $\left(p<0.001, R^{2}=0.37\right.$ for 28 species, Figure $1 \mathrm{a} ; R^{2}=0.35, p=0.007$ for forbs; not significant for grasses, $p=0.143$, Figure 2).

Leaf litter decomposition rate was not significantly linked to the intensity of mycorrhizal colonization, both in restricted (20 species) and extended (62 species; Figure 1b) data sets, also for grasses or forbs taken separately (data not shown). The relationship between RGR and leaf litter decomposition was not significant for all species together (Figure 1c) or for grasses and forbs separately.

A high level of mycorrhizal colonization intensity was observed mostly for species with high relative abundance (Table 1, Figure 3a).
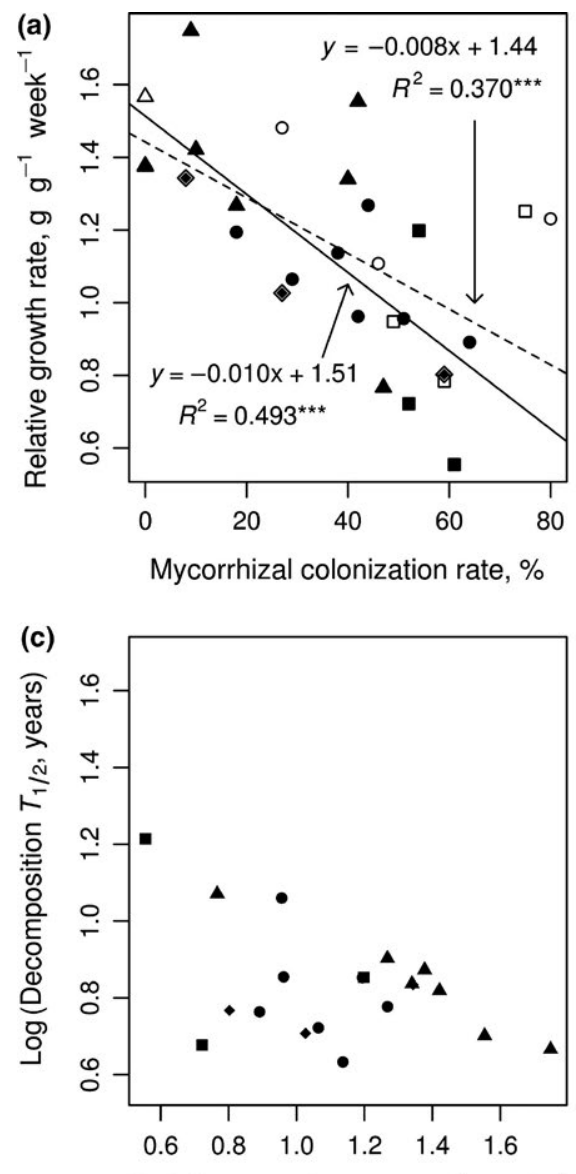

Relative growth rate, $\mathrm{g} \mathrm{g}^{-1}$ week $^{-1}$

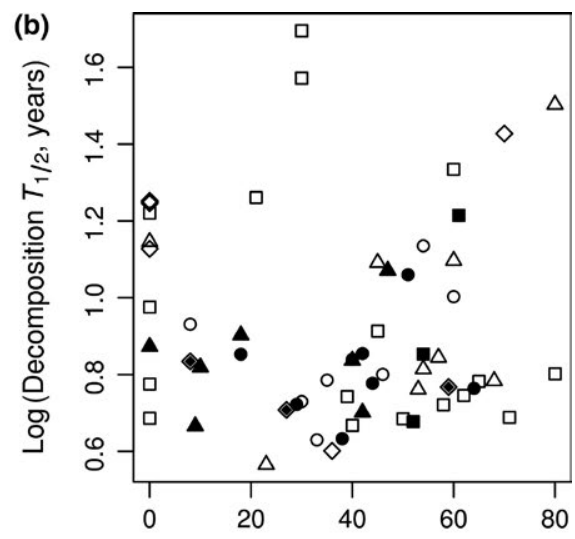

Mycorrhizal colonization rate, \%

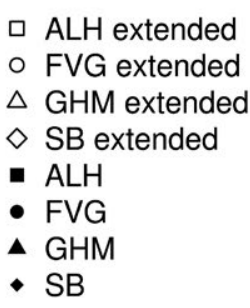

--- extended

- for 20 species
FIGURE 1 Relationships between traits of alpine plant species: (a) intensity of mycorrhizal colonization and relative growth rate (RGR); (b) intensity of mycorrhizal colonization and decomposition half-life; (c) RGR and decomposition half-life for 20 species. Panels (a,b) show results for the 20 species trait data set (set of species included in all analyses; solid regression line in [a]) and for extended data sets (dashed regression line in [a]). Open symbols are for extended data set, filled symbols for 20 species. ${ }^{* * *} p<0.001$ 
RGR negatively predicted relative abundance (Table 1, Figure 3b), so subordinate species tended to grow fast, while dominants were slow-growing. Decomposition rate did not show any significant relationship with field biomass.

\section{4 | DISCUSSION}

The intensity of plant root mycorrhizal colonization was a good (negative) predictor of RGR measured in the pot experiment at low fertility soil conditions and without mycorrhizal inoculum. This is consistent with the view that under nutrient limitation, such as in the alpine communities at our site (Onipchenko et al., 2012), the capacity for mycorrhizal association is a strong adaptive mechanism for nutrient uptake for species with inherent low growth rates. Indeed,

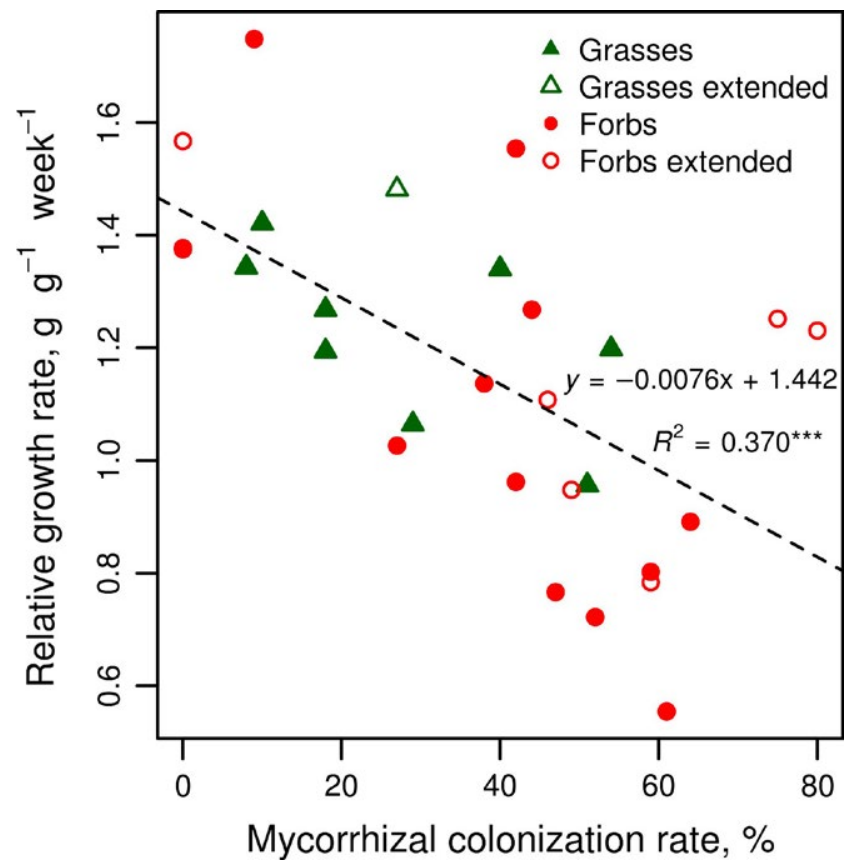

FIGURE 2 Relationships between intensity of mycorrhizal colonization and relative growth rate for grasses and forbs of 20 species and for the extended data set. Regression line is displayed for the extended data set. ${ }^{* * *} p<0.001$ [Colour figure can be viewed at wileyonlinelibrary.com] many obligatory mycorrhizal species occur on infertile soils (Hempel et al., 2013). Although mycorrhizal plants invest carbohydrates not only into their own above- and below-ground growth, but also into fungal hyphae (Leake et al., 2004; Orwin, Kirshbaum, St John \& Dickie, 2011; Smith \& Read, 2008), the extent of restriction to plant growth rate capacity from this investment may depend on the species identity and local environmental factors (Smith et al., 2010). In some cases the sink for $\mathrm{C}$ in mycorrhizal fungi promotes a higher rate of photosynthesis, as shown for legumes, and does not reduce growth rate and biomass of mycorrhizal plants (Kaschuk, Kuyper, Leffelaar, Hungria \& Giller, 2009; Wright, Scholes \& Read, 1998). At low nutrient availability, specimens of slow-growing plant species may grow faster when colonized by mycorrhizal fungi, compared to non-mycorrhizal individuals of the same species, as shown for six vascular plant species (Aikio \& Ruotsalainen, 2002). Thus, mycorrhizae support the growth of species with lower inherent RGR under low-nutrient field conditions.

The hypothesized negative relationship between RGR and mycorrhizal colonization rate was observed across all grasses and forbs in our study. However, when these groups were examined separately, the relationship was significant only for forbs. Forbs are a taxonomically heterogeneous group with high inter-specific trait diversity (Kattge et al., 2011). The forbs examined in our study included both non-mycorrhizal fast-growing species, such as R. alpestris, and slowgrowing species with a rather high rate of mycorrhizal colonization, such as A. dioica. Among the species with a particularly low RGR were two legumes (Trifolium polyphyllum and H.caucasicum); this functional group generally has rather low RGR in comparison with grasses (Reich et al., 2003). Clonality is an important plant trait as it promotes resource translocation and storage, which may act as an alternative to mycorrhizal symbiosis in alpine communities. As a consequence, vegetatively mobile plants tend to have lower rate of AM colonization (Onipchenko \& Zobel, 2000). All grasses examined in this study were clonal and thus did not exhibit high values of AM colonization. Also a lower number of grass species included into the analysis might have reduced the significance of the relationship between RGR and mycorrhizal colonization in that group.

Contrary to our expectations, we did not find a clear relationship between plant species litter decomposability and the intensity of plant root colonization by AM fungi. This was despite the fact

TAB LE 1 Impacts of mycorrhizal colonization intensity, relative growth rate (RGR), decomposition rate (Decomposition $T_{1 / 2}$ ) on relative biomass of alpine plant species (results of linear mixed effect models)

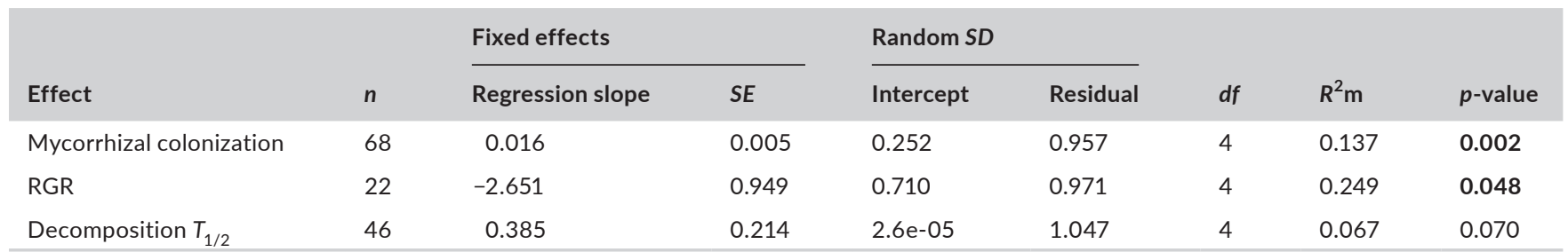

Notes. $p$-values are assessed by model comparison (full model with given fixed effect and null model without it) using likelihood ratio. Significant $p$-values are highlighted in bold.

$\mathrm{N}$ : number of species; $R^{2} \mathrm{~m}$ : marginal coefficient of determination (for variance explained by fixed effects); SE: standard error of the regression slope. 


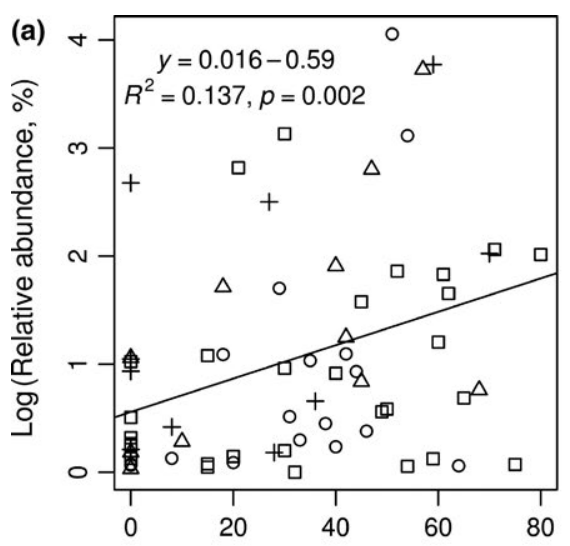

Mycorrhizal colonization rate, \%

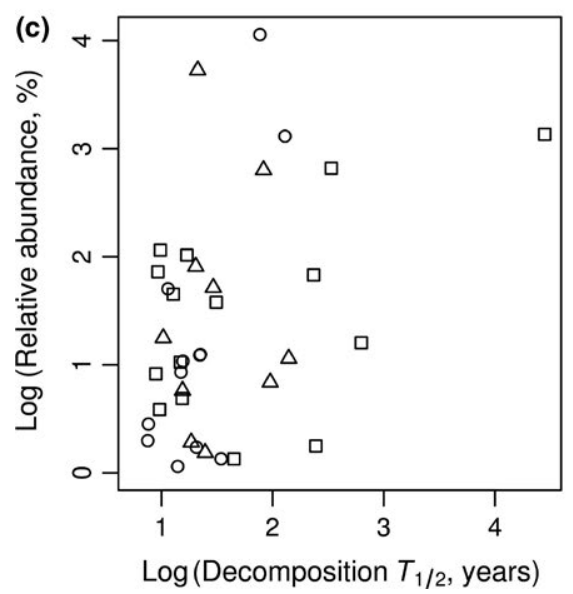

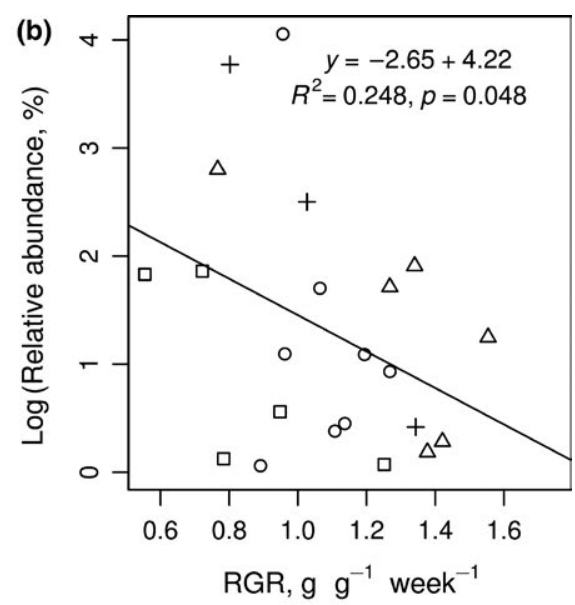

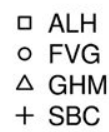

口 ALH

○ FVG

$+\mathrm{SBC}$ that RGR exhibited a tendency to be positively associated with leaf litter decomposition rate, and plant species RGR correlates negatively with intensity of plant root colonization by mycorrhizal fungi. Two mechanisms working in opposite directions might have underpinned this absence of a relationship. On the one hand, plants with low RGR (having, as we found, high rate of mycorrhizal colonization) typically have a low specific leaf area (Hunt \& Cornelissen, 1997) and low nutrient content in litter tissues, both traits retarding decomposition (Cornwell et al., 2008). On the other hand, inherently slow-growing species with a mycorrhizal association in natural communities are expected to have improved nutrient status, which in turn should result in higher litter nutrient content, and therefore greater decomposability. Also, decomposability of non-mycorrhizal species shows high inter-specific variation, which contributes to the overall relationship. Together, these counteracting drivers of leaf trait variation might explain why we did not find a clear relationship between species litter decomposability and infection by AM fungi. Thus the role of arbuscular mycorrhizal colonization rate in $\mathrm{C}$ and nutrient cycling is not straightforward and requires further in-depth investigation, using larger field-collected data sets. Novel methods, such as structural equation modelling (Shipley, 2000), could be used to explain complex linkages between the mycorrhizae and other factors driving $C$ and nutrient cycling in alpine ecosystems.
Our findings are consistent with the view that AM fungi in nutrient-limited alpine habitats support the dominance of slowgrowing plant species. Based on analysis of a German flora, Hempel et al. (2013) suggested that species featuring a competitor strategy (Grime, 2001) usually are obligatory mycorrhizal, while stress-tolerant species, especially those growing under extreme nutrient stress, are often non-mycorrhizal. In general, we found that dominant species of alpine communities have low RGR and a high level of mycorrhizal infection. These features are adaptations to nutrient-poor soil and represent the stress-tolerant strategy (Chapin, 1980; Grime, 1979). Similar patterns were described for an infertile pasture site in Ontario (Reader, 1998) and for alpine communities in Colorado (Theodose, Jaeger, Bowman \& Schardt, 1996), where the traits reflecting adaptations of plants to poor soils were good predictors of species dominance. However, given that our study focuses on AM species only, the question if these findings apply to other mycorrhizal types remains open. It is known that ericoid mycorrhizal fungi and (partly) ectomycorrhizal fungi tend to associate with plant species with strong stress tolerance features in habitats with low $\mathrm{N}$ availability (Smith \& Read, 2008). The extent to which the intensity of mycorrhizal colonization by these types of fungi is related to level of dominance of these plants in the plant community needs investigation. 
Our study is among the first using the intensity of mycorrhizal colonization as a functional plant trait in a field non-experimental investigation. The value of using plant mycorrhizal traits obtained from trait databases is often discussed (Moora, 2014; Soudzilovskaia et al., 2015). Recently, using the database-extracted values of per plant species mycorrhizal colonization intensity, Soudzilovskaia et al. (2015) have shown that in field conditions, mycorrhizal colonization rate is a less variable trait than previously considered, i.e. the extent of its variability is comparable to that of other traits. This suggests that mycorrhizal colonization rate could be considered in analyses of trait-trait relationships aiming to improve our understanding of mechanisms of plant ecophysiological adaptations to the environment. Indeed, recently Li, Liu, McCormack, Ma and Guo (2017) have shown that intensity of mycorrhizal colonization is closely connected to plant root traits. The current study constitutes one of the first attempts to systematically use field-measured values of mycorrhizal colonization rate as a functional trait to compare to the aboveground field-measured traits and to explain relationships between plant community structure, i.e. abundance of individual plant species and ecophysiological strategies of these species. Altogether, our analysis highlights the importance of mycorrhizal fungi as a key component of the overall plant nutrient and $\mathrm{C}$ economic strategies in herbaceous communities on soils with nutrient limitation to productivity. Our findings highlight interesting connections among interspecific variation in field abundance, mycorrhizal colonization and RGR, such as the dominance of slow-growing species with support from these fungi.

\section{ACKNOWLEDGEMENTS}

We are grateful to Mikhail N. Maslov for help in sample harvesting. The study was supported by (Dutch) NWO grants 047.017 .010 and 047.018.003. V.O. thanks RSF (Grant No. 16-14-10208) for financial support.

\section{ORCID}

Tatiana G. Elumeeva (iD http://orcid.org/0000-0003-0589-830X

\section{REFERENCES}

Aikio, S., \& Ruotsalainen, A. L. (2002). The modelled growth of mycorrhizal and not-mycorrhizal plants under constant versus variable soil nutrient concentration. Mycorrhiza, 12, 257-261. https://doi. org/10.1007/s00572-002-0178-5

Akhmetzhanova, A. A., Soudzilovskaia, N. A., Onipchenko, V. G., Cornwell, W. K., Agafonov, V. A., Selivanov, I. A., \& Cornelissen, J. H. C. (2012). A rediscovered treasure: Mycorrhizal intensity database for 3000 vascular plant species across the former Soviet Union. Ecology, 93, 689-690. https://doi.org/10.1890/11-1749.1

Allen, M. F., Swenson, W., Querejeta, J. I., Egerton-Warburton, L. M., \& Treseder, K. K. (2003). Ecology of mycorrhizae: A conceptual framework for complex interactions among plants and fungi. Annual Review of Phytopathology, 41, 271-303. https://doi.org/10.1146/annurev. phyto.41.052002.095518
Atkin, O. K., Botman, B., \& Lambers, H. (1996). The causes of inherently slow growth in alpine plants: An analysis based on the underlying carbon economies of alpine and lowland Poa species. Functional Ecology, 10, 698-707. https://doi.org/10.2307/2390504

Bardgett, R. D. (2017). Plant trait-based approaches for interrogating belowground function. Biology and Environment: Proceedings of the Royal Irish Academy, 117B, 1-13.

Bardgett, R. D., \& Wardle, D. A. (2010). Aboveground-belowground linkages. Biotic interactions, ecosystem processes, and global change. Oxford, UK: Oxford University Press.

Birhane, E., Sterck, F. J., Fetene, M., Bongers, F., \& Kuyper, T. W. (2012). Arbuscular mycorrhizal fungi enhance photosynthesis, water use efficiency, and growth of frankincense seedlings under pulsed water availability conditions. Oecologia, 169, 895-904. https://doi. org/10.1007/s00442-012-2258-3

Chagnon, P.-L., Bradley, R. L., Maherali, H., \& Klironomos, J. (2013). A trait-based framework to understand life history of mycorrhizal fungi. Trends in Plant Science, 18, 484-491. https://doi.org/10.1016/j. tplants.2013.05.001

Chapin, F. S. I. I. I. (1980). The mineral nutrition of wild plants. Annual Review of Ecology and Systematics, 11, 233-260. https://doi. org/10.1146/annurev.es.11.110180.001313

Cherednichenko, O.V., Onipchenko, V.G., Zakharov, A.A., Makarov, M.I., Golikov, K.A., Blinkova, O.V., \& Blinnikov, M.S. Structure and dynamics of closed alpine communities. In V. G. Onipchenko (Ed.), Alpine ecosystems in the Northwestern Caucasus (pp. 77-179). Dordrecht, NL: Kluwer. https://doi.org/10.1007/978-1-4020-2383-5

Cornelissen, J. H. C. (1996). An experimental comparison of leaf decomposition rates in a wide range of temperate plant species and types. Journal of Ecology, 84, 573-582. https://doi.org/10.2307/ 2261479

Cornelissen, J. H. C., Aerts, R., Cerabolini, B., Werger, M. J. A., \& van der Heijden, M. G. A. (2001). Carbon cycling traits of plant species are linked with mycorrhizal strategy. Oecologia, 129, 611-619. https:// doi.org/10.1007/s004420100752

Cornwell, W. K., Cornelissen, J. H. C., Amatangelo, K., Dorrepaal, E., Eviner, V. T., Godoy, O., ... Westoby, M. (2008). Plant species traits are the predominant control on litter decomposition rates within biomes worldwide. Ecology Letters, 11, 1065-1071. https://doi. org/10.1111/j.1461-0248.2008.01219.x

Facelli, J. M., \& Pickett, S. T. A. (1991). Plant litter: Its dynamics and effects on plant community structure. Botanical Review, 57, 1-32. https://doi.org/10.1007/BF02858763

Fortunel, C., Garnier, E., Joffre, R., Kazakou, E., Quested, H., Grigulis, C., ... Zarovali, M. (2009). Leaf traits capture the effects of land use changes and climate on litter decomposability of grasslands across Europe. Ecology, 90, 598-611. https://doi. org/10.1890/08-0418.1

Francis, R., \& Read, D. J. (1995). Mutualism and antagonism in the mycorrhizal symbiosis, with special reference to impacts on plant community structure. Canadian Journal of Botany, 73(suppl.), 1301-1309. https://doi.org/10.1139/b95-391

Freschet, G. T., Aerts, R., \& Cornelissen, J. H. C. (2012). A plant economics spectrum of litter decomposability. Functional Ecology, 26, 56-65. https://doi.org/10.1111/j.1365-2435.2011.01913.x

Garnier, E., Navas, M.-L., \& Grigulis, K. (2016). Plant functional diversity: Organism traits, community structure and ecosystem properties. Oxford, UK: Oxford University Press.

Grime, J. P. (1979). Plant strategies and vegetative processes. Chichester, UK: Wiley \& Sons.

Grime, J. P. (2001). Plant strategies, vegetation processes, and ecosystem properties. Chichester, UK: Wiley.

Grime, J. P., Hodgson, J. G., \& Hunt, R. (1988). Comparative plant ecology: A functional approach to common British species. London, UK: Hyman. https://doi.org/10.1007/978-94-017-1094-7 
Grime, J. P., Mackey, J. M. L., Hillier, S. H., \& Read, D. J. (1987). Floristic diversity in a model system using experimental microcosms. Nature, 328, 420-422. https://doi.org/10.1038/328420a0

Gross, N., Le Bagousse-Pinguet, Y., Liancourt, P., Urcelay, C., Roumet, C., \& Lavorel, S. (2010). Trait-mediated effect of arbuscular mycorrhiza on the competitive effect and response of a monopolistic species. Functional Ecology, 24, 1122-1132. https://doi. org/10.1111/j.1365-2435.2010.01713.x

Hartnett, D. C., \& Wilson, G. W. T. (1999). Mycorrhizae influence plant community structure and diversity in tall grass prairie. Ecology, 80, 1187-1195. https://doi.org/10.1890/0012-9658(1999)080[1187:MI PCSA]2.0.CO;2

Hempel, S., Hötzenberger, L., Kühn, I., Michalski, S. G., Rillig, M. C., Zobel, M., \& Moora, M. (2013). Mycorrhizas in the Central European Flora: Relationships with plant life history traits and ecology. Ecology, 94, 1389-1399. https://doi.org/10.1890/12-1700.1

Herman, D. J., Firestone, M. K., Nuccio, E., \& Hodge, A. (2012). Interactions between an arbuscular mycorrhizal fungus and a soil microbial community mediating litter decomposition. FEMS Microbiology Ecology, 80, 236-247. https://doi.org/10.1111/j.1574-6941.2011.01292.x

Hodge, A., Campbell, C. D., \& Fitter, A. H. (2001). An arbuscular mycorrhizal fungus accelerates decomposition and acquires nitrogen directly from organic material. Nature, 413, 297-299. https://doi. org/10.1038/35095041

Hunt, R., \& Cornelissen, J. H. C. (1997). Components of relative growth rate and their interrelations in 59 temperate plant species. New Phytologist, 135, 395-417. https://doi.org/10.1046/j.1469-8137.1997.00671.x

Jin, L., Wang, Q., Wang, Q., Wang, X., \& Gange, A. C. (2017). Mycorrhizalinduced growth depression in plants. Symbiosis, 72, 81-88. https:// doi.org/10.1007/s13199-016-0444-5

Kaschuk, G., Kuyper, T. W., Leffelaar, P. A., Hungria, M., \& Giller, K. E. (2009). Are the rates of photosynthesis stimulated by the carbon sink of rhizobial and arbuscular mycorrhizal symbioses? Soil Biology and Biochemistry, 41, 1233-1244. https://doi.org/10.1016/j. soilbio.2009.03.005

Kattge, J., Díaz, S., Lavorel, S., Prentice, I. C., Leadley, P., Bönisch, G., ... Wirth, C. (2011). TRY - a global database of plant traits. Global Change Biology, 17, 2905-2935. https://doi.org/10.1111/j.13652486.2011.02451.x

Kazakou, E., Vile, D., Shipley, B., Gallet, C., \& Garnier, E. (2006). Covariations in litter decomposition, leaf traits and plant growth in species from a Mediterranean old-field succession. Functional Ecology, 20, 21-30. https://doi.org/10.1111/j.1365-2435.2006. 01080.x

Konvalniková, T., Püschel, D., Řezáčová, V., Gryndlerová, H., \& Jansa, J. (2017). Carbon flow from plant to arbuscular mycorrhizal fungi is reduced under phosphorus fertilization. Plant and Soil, 419, 319-333. https://doi.org/10.1007/s11104-017-3350-6

Langley, J. A., \& Hungate, B. A. (2003). Mycorrhizal controls on belowground litter quality. Ecology, 84, 2302-2312. https://doi. org/10.1890/02-0282

Leake, J. R., Johnson, D., Donnely, D. P., Muckle, G. E., Boddy, L., \& Read, D. J. (2004). Networks of power and influence: The role of mycorrhizal mycelium in controlling plant communities and agroecosystem functioning. Canadian Journal of Botany, 82, 1016-1045. https://doi. org/10.1139/b04-060

Leigh, J., Hodge, A., \& Fitter, A. H. (2009). Arbuscular mycorrhizal fungi can transfer substantial amounts of nitrogen to their host plant from organic material. New Phytologist, 181, 199-207. https://doi. org/10.1111/j.1469-8137.2008.02630.x

Li, H., Liu, B., McCormack, M. L., Ma, Z., \& Guo, D. (2017). Diverse belowground resource strategies underlie plant species coexistence and spatial distribution in three grasslands along a precipitation gradient. New Phytologist, 216, 1140-1150. https://doi.org/10.1111/ nph.14710
Malysheva, T. I., Onipchenko, V. G., Makarov, M. I., Volkov, A. V., \& Bulatnikova, I. V. (2004). Soils and nutrient turnover. In V. G. Onipchenko (Ed.), Alpine ecosystems in the Northwestern Caucasus (pp. 9-23). Dordrecht, NL: Kluwer. https://doi. org/10.1007/978-1-4020-2383-5

Mariotte, P., Meugnier, C., Johnson, D., Thébault, A., Spiegelberger, T., $\&$ Buttler, A. (2013). Arbuscular mycorrhizal fungi reduce the differences in competitiveness between dominant and subordinate plant species. Mycorrhiza, 23, 267-277. https://doi.org/10.1007/ s00572-012-0465-8

McCain, K. N. S., Wilson, G. W. T., \& Blair, J. M. (2011). Mycorrhizal suppression alters plant productivity and forb establishment in a grassdominated prairie restoration. Plant and Soil, 212, 1675-1685.

Moora, M. (2014). Mycorrhizal traits and plant communities: Perspectives for integration. Journal of Vegetation Science, 25, 1126-1132. https:// doi.org/10.1111/jvs.12177

Nakagawa, S., \& Schielzeth, H. (2013). A general and simple method for obtaining $R^{2}$ from generalized linear mixed-effects models. Methods in Ecology and Evolution, 4, 133-142. https://doi. org/10.1111/j.2041-210x.2012.00261.x

Nuccio, E. E., Hodge, A., Pett-Ridge, J., Herman, D. J., Weber, P. K., \& Firestone, M. K. (2013). An arbuscular mycorrhizal fungus significantly modifies the soil bacterial community and nitrogen cycling during litter decomposition. Environmental Microbiology, 15, 18701881. https://doi.org/10.1111/1462-2920.12081

Onipchenko, V. G. (1994). The structure and dynamics of alpine plant communities in the Teberda Reserve, the Northwestern Caucasus. Oecologia Montana, 3(35), 45.

Onipchenko, V. G. (2004). Geography, geology, climate and the communities studied. In V. G. Onipchenko (Ed.), Alpine ecosystems in the Northwestern Caucasus (pp. 1-7). Dordrecht, NL: Kluwer. https://doi. org/10.1007/978-1-4020-2383-5

Onipchenko, V. G., Makarov, M. I., Akhmetzhanova, A. A., Soudzilovskaia, N. A., Aibazova, F. U., Elkanova, M. K., ... Cornelissen, J. H. C. (2012). Alpine functional group responses to fertilizer addition depend on abiotic regime and community composition. Plant and Soil, 357, 103-115. https://doi.org/10.1007/ s11104-012-1146-2

Onipchenko, V. G., Semenova, G. V., \& van der Maarel, E. (1998). Population strategies in severe environments: Alpine plants in the northwestern Caucasus. Journal of Vegetation Science, 9, 27-40. https://doi.org/10.2307/3237220

Onipchenko, V. G., Zernov, A. S., \& Vorob'eva, F. M. (2011). Vascular plants of Teberda Reserve (annotated list of species), 2nd ed. Flora and fauna of natural reserves, 99A. Moscow, Russia: MAKS Press.

Onipchenko, V. G., \& Zobel, M. (2000). Mycorrhiza, vegetative mobility and responses to disturbance of alpine plants in the Northwestern Caucasus. Folia Geobotanica, 35, 1-11. https://doi.org/10.1007/ BF02803083

Orwin, K. H., Kirshbaum, M. U. F., St John, M. G., \& Dickie, I. A. (2011). Organic nutrient uptake by mycorrhizal fungi enhances ecosystem carbon storage: A model-based assessment. Ecology Letters, 14, 493502. https://doi.org/10.1111/j.1461-0248.2011.01611.x

Pierce, S., Negreiros, D., Cerabolini, B. E. L., Kattge, J., Díaz, S., Kleyer, M., ... Tampucci, D. (2017). A global method for calculating plant CSR ecological strategies applied across biomes world-wide. Functional Ecology, 31, 444-457. https://doi.org/10.1111/1365-2435.12722

Reader, R. J. (1998). Relationship between species relative abundance and plant traits for an infertile habitat. Plant Ecology, 134, 43-51. https://doi.org/10.1023/A:1009700100343

Reich, P. B., Buschena, C., Tjoelker, M. G., Wrage, K., Knops, J., Tilman, D., \& Machado, J. L. (2003). Variation in growth rate and ecophysiology among 34 grassland and savanna species under contrasting $\mathrm{N}$ supply: A test of functional group differences. New Phytologist, 157, 617-631. https://doi.org/10.1046/j.1469-8137.2003.00703.x 
Rillig, M. C., \& Allen, M. F. (1999). What is the role of arbuscular mycorrhizal fungi in plant-to-ecosystem responses to elevated atmospheric $\mathrm{CO}_{2}$ ? Mycorrhiza, 9, 1-8. https://doi.org/10.1007/s005720050257

Ruotsalainen, A. L., Väre, H., \& Vestberg, M. (2002). Seasonality of root fungal colonization in low-alpine herbs. Mycorrhiza, 12, 29-36. https://doi.org/10.1007/s00572-001-0145-6

Schädler, M., Brandl, R., \& Kempel, A. (2010). "Afterlife" effects of mycorrhization on the decomposition of plants residues. Soil Biology and Biochemistry, 42, 521-523. https://doi.org/10.1016/j. soilbio.2009.11.031

Selivanov, I. A. (1981). Mycosymbiotrophy as a form of consortic relationship in vegetation of the Soviet Union. Moscow, Russia: Nauka.

Shipley, B. (2000). Cause and correlation in biology. A user's guide to path analysis, structural equations and causal inference. Cambridge, UK: Cambridge University Press.

Smith, S. E., Facelli, E., Pope, S., \& Smith, F. A. (2010). Plant performance in stressful environments: Interpreting new and established knowledge of the roles of arbuscular mycorrhizas. Plant and Soil, 326, 3-20. https://doi.org/10.1007/s11104-009-9981-5

Smith, S. E., \& Read, D. J. (2008). Mycorrhizal symbiosis. London, UK: Academic Press.

Sogonov, M.V., Velicanov, L.L., Tarasov, K.L., Onipchenko, V.G., Leinsoo, T.N., \& Stepanov, A.L., Fungi, mycorrhiza, and mycrobiological processes in the alpine ecosystems. In V. G. Onipchenko (Ed.), Alpine ecosystems in the Northwestern Caucasus (pp. 271-302). Dordrecht, NL: Kluwer. https://doi.org/10.1007/978-1-4020-2383-5

Son, C. L., \& Smith, S. E. (1988). Mycorrhizal growth responses: Interactions between photon irradiance and phosphorus nutrition. New Phytologist, 108, 305-314. https://doi. org/10.1111/j.1469-8137.1988.tb04167.x

Soudzilovskaia, N. A., Onipchenko, V. G., Cornelissen, J. H. C., \& Aerts, R. (2005). Biomass production, N: P ratio and nutrient limitation in a Caucasian alpine tundra. Journal of Vegetation Science, 16, 399-406. https://doi.org/10.1111/j.1654-1103.2005.tb02379.x

Soudzilovskaia, N. A., van der Heijden, M. G. A., Cornelissen, J. H. C., Makarov, M. I., Maslov, M. N., Akhmetzhanova, A. A., \& van Bodegom, P. M. (2015). Quantitative assessment of the differential impacts of arbuscular and ectomycorrhiza on soil carbon cycling. New Phytologist, 208, 280-293. https://doi.org/10.1111/ nph.13447

Stanescu, S., \& Maherali, H. (2017a). Mycorrhizal feedback is not associated with the outcome of competition in old-field perennial plants. Oikos, 126, 248-258.

Stanescu, S., \& Maherali, H. (2017b). Arbuscular mycorrhizal fungi alter the competitive hierarchy among old-field plant species. Oecologia, 183, 479-491. https://doi.org/10.1007/s00442-016-3771-6

Theodose, T. A., Jaeger, C. H. I. I. I., Bowman, W. D., \& Schardt, J. C. (1996). Uptake and allocation of $\mathrm{N}^{15}$ in alpine plants: Implications for the importance of competitive ability in predicting community structure in a stressful environment. Oikos, 75, 59-66. https://doi.org/10.2307/ 3546321

Treseder, K. K. (2013). The extent of mycorrhizal colonization of roots and its influence on plant growth and phosphorus content. Plant and Soil, 371, 1-13. https://doi.org/10.1007/s11104-013-1681-5 van der Heijden, M. G. A., Bardgett, R. D., \& van Straalen, N. M. (2008). The unseen majority: Soil microbes as drivers of plant diversity and productivity in terrestrial ecosystems. Ecology Letters, 11, 296-310. https://doi.org/10.1111/j.1461-0248.2007.01139.x

van der Heijden, M. G. A., \& Cornelissen, J. H. C. (2002). The critical role of plant-microbe interactions for biodiversity and ecosystem functioning: Arbuscular mycorrhizal associations as an example. In M. Loreau, S. Naeem, \& P. Inchausti (Eds.), Biodiversity and ecosystem functioning: Synthesis and perspectives (pp. 181-192). Oxford, UK: Oxford University Press.

van der Heijden, M. G. A., Martin, F. M., Selosse, M.-A., \& Sanders, I. R. (2015). Mycorrhizal ecology and evolution: The past, the present, and the future. New Phytologist, 205, 1406-1423. https://doi. org/10.1111/nph.13288

Varga, S., \& Kytöviita, M.-M. (2016). Faster acquisition of symbiotic partner by common mycorrhizal networks in early plant life stage. Ecosphere, 7(1), e01222. https://doi.org/10.1002/ecs.2.1222

Wright, D. P., Scholes, J. D., \& Read, D. J. (1998). Effects of VA mycorrhizal colonization on photosynthesis and biomass production of Trifolium repens L. Plant, Cell and Environment, 21, 209-216. https:// doi.org/10.1046/j.1365-3040.1998.00280.x

Xiong, S., \& Nilsson, C. (1999). The effects of plant litter on vegetation: A meta-analysis. Journal of Ecology, 87, 984-994. https://doi. org/10.1046/j.1365-2745.1999.00414.x

\section{SUPPORTING INFORMATION}

Additional supporting information may be found online in the Supporting Information section at the end of the article.

Appendix S1 Relative growth rate (RGR), leaf litter decomposition half-life $\left(T_{1 / 2}\right)$, intensity of mycorrhizal infection, and biomass of alpine species

Appendix S2 Soil characteristics of four studied alpine communities: alpine lichen heath (ALH), Festuca varia grassland (FVG), GeraniumHedysarum meadow (GHM), alpine snowbed (SB) (from Onipchenko 1994)

Appendix S3 Results of the models testing relationships between $R G R$, decomposition $T_{1 / 2}$ and mycorrhizal colonization for the extended data set

How to cite this article: Elumeeva TG, Onipchenko VG, Cornelissen JHC, et al. Is intensity of plant root mycorrhizal colonization a good proxy for plant growth rate, dominance and decomposition in nutrient poor conditions? J Veg Sci. 2018;29:715-725. https://doi.org/10.1111/jvs.12651 